\title{
Retropharyngeal Tendonitis: A Cause of Severe Neck Pain
}

\author{
Edward J. Kakish ${ }^{\mathrm{a}, \mathrm{c}}$, Jonathan R. Demory ${ }^{\mathrm{a}}$, Viviane Kazan ${ }^{\mathrm{a}}$, Alex Moore ${ }^{\mathrm{b}}$, \\ Patricia Paz-Arabo ${ }^{\mathrm{b}}$
}

\begin{abstract}
The clinical presentation of calcific retropharyngeal tendonitis, a rare entity, can mimic more serious disorders. The main stay of diagnosis is CT scan that shows calcification of $\mathrm{C} 1-\mathrm{C} 2$ which is pathognomonic. Here we present a case of a 26 -year-old man presenting to the emergency department (ED) with a chief complaint of neck pain that increased in severity. The patient was first diagnosed with torticollis and sent home on painkillers. Further tests were ordered upon his return to the ED complaining of increased neck pain severity and dysphagia. Diagnosis was ultimately made by CT scan and the patient was treated accordingly. When misdiagnosed, patients with retropharyngeal tendonitis can often undergo unnecessary and invasive surgical procedures to drain nonexistent abscesses. With proper imaging, and an informed physician, correct diagnosis can be made based on prevertebral swelling and calcification.
\end{abstract}

Keywords: Retropharyngeal tendonitis; Neck pain; Retropharyngeal abscess

\section{Introduction}

Retropharyngeal tendonitis is a self-limiting inflammatory disease involving the longus colli muscle. It was not until 1964 that Hartley reported the first case of cervical pain associated with calcium deposits in these fibers [1]. It commonly presents with vague symptoms such as neck pain (94\%), limited movement (45\%), odynophagia (45\%), stiffness ( $42 \%$ ) and dysphasia $(27 \%)$ [2]. Located in the prevertebral area, the longus colli muscle assists in flexion and rotation of the neck, and takes up

Manuscript accepted for publication September 07, 2015

aDepartment of Emergency Medicine, The University of Toledo Medical Center, 3000 Arlington Avenue, Mail Stop 1088, Toledo, OH 43614, USA

bepartment of Emergency Medicine, St. Mary Mercy Hospital, 36475 Five Mile Road, Livonia, MI 48154, USA

${ }^{\mathrm{c} C o r r e s p o n d i n g ~ A u t h o r: ~ E d w a r d ~ K a k i s h, ~ T h e ~ U n i v e r s i t y ~ o f ~ T o l e d o ~ M e d i c a l ~}$ Center, 3000 Arlington Ave., Mail Stop 1088, Toledo, OH 43614, USA.

Email: Edward.kakish@utoledo.edu

doi: http://dx.doi.org/10.14740/jmc2286w most of the retropharyngeal space. The longus colli consists of three muscle groups: the superior oblique, vertical and inferior oblique. In retropharyngeal tendonitis, the pain is caused by calcium hydroxyapatite crystal deposition in the superior oblique fibers, which attach from the transverse processes of C3-C5 to the ventral arch of the atlas [3]. The pathophysiology is still unclear, although several cases have been reported after trauma, infection and even in the case of intubation in the emergency department (ED) [4]. Although deposition occurs in the tendon, the majority of swelling is observed in the belly of the muscle itself, which can be mistaken for a retropharyngeal abscess [5]. There has been a recent surge in publications in the emergency medicine literature on retropharyngeal tendonitis, with several cases reported in the last 2 years [6-8]. Here we present a case of a 26 -year-old male presenting to the ED complaining of neck pain.

\section{Case Report}

A 26-year-old male with no significant past medical history presented to the ED with persistent left-sided neck pain. He had been seen the previous day at an urgent care. At that initial visit, he denied fever, chills, sore throat, or difficulty swallowing. The patient did report similar episodes in the past with spontaneous resolution of his symptoms. Physical exam was notable for pain with movement of the patient's neck and palpation of the left lateral trapezius. X-ray of the soft tissue of the neck was unremarkable. The diagnosis of torticollis was made and the patient was given flexeril and Tylenol with codeine. The next day in the ED, the patient reported that the neck pain persisted and he developed difficulty swallowing. Exam again revealed pain with active flexion of his neck. Electrolytes, kidney function, and white blood cell count (WBC) was normal. CT of the soft tissue of the neck showed a retropharyngeal fluid density extending from $\mathrm{C} 2$ to $\mathrm{C} 6$ with associated anterior soft tissue calcification from $\mathrm{C} 1$ to $\mathrm{C} 2$ measuring 5 - $6 \mathrm{~mm}$ (Fig. 1). The radiologist stated that these findings were consistent with retropharyngeal calcific tendonitis. However, the possibility of retropharyngeal abscess could not be completely excluded at that time. A retropharyngeal abscess was unlikely because the patient was without fever, was non-toxic appearing, and had a normal WBC. The patient was admitted to the hospital for pain control and further evaluation by ENT and 


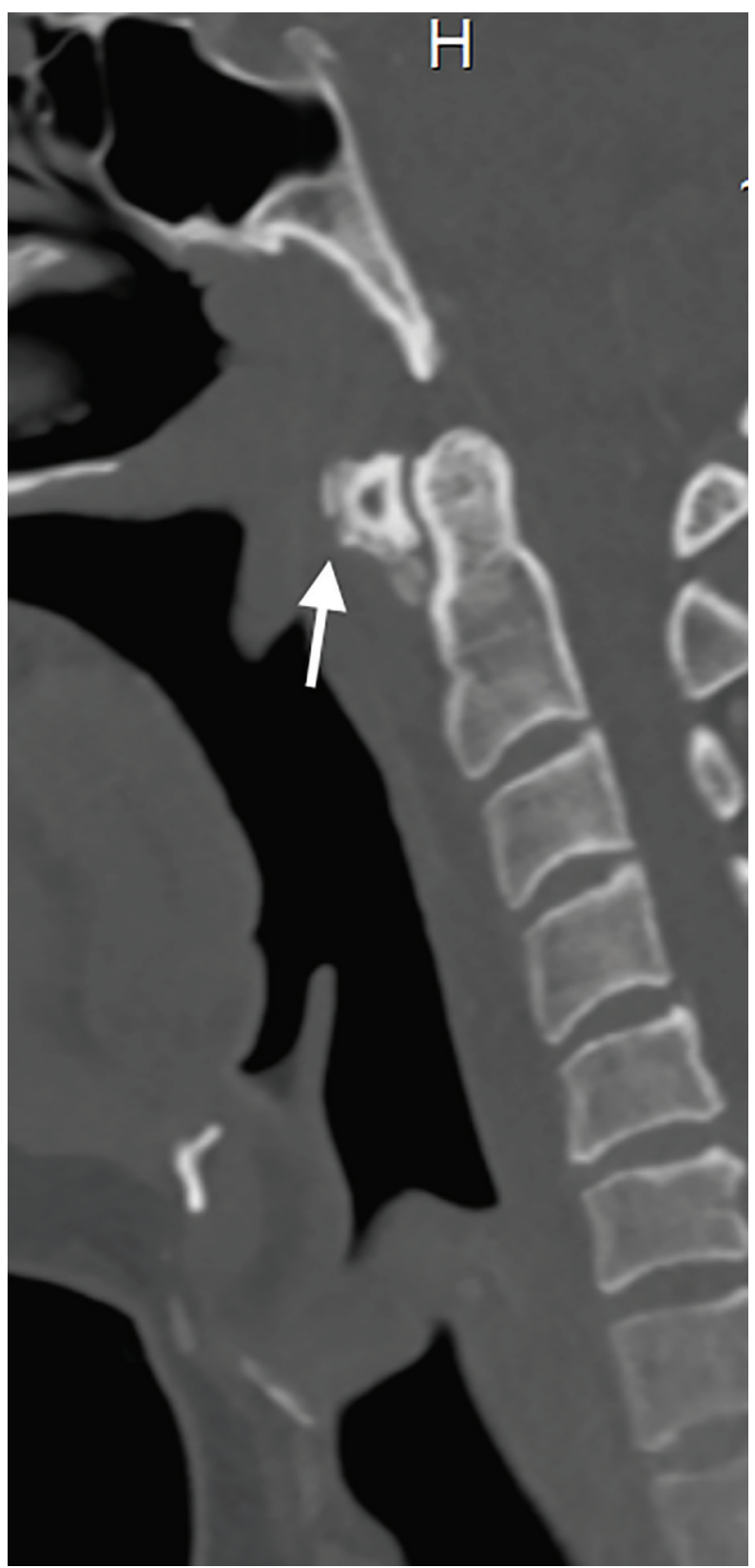

Figure 1. CT scan of the neck with anterior soft tissue calcification (white arrow).

infectious disease. Ketoralac $30 \mathrm{mg}$ IV q6h, a non-steroidal anti-inflammatory drugs (NSAIDs), for pain control and clindamycin $300 \mathrm{mg}$ IV q8h were started. Cyclobenzaprine $5 \mathrm{mg}$ PO q8h prn for muscle spasms and diazepam $5 \mathrm{mg}$ IV q6h PRN also for muscle spasms were given. On hospital day 2, the patient was seen by ENT. The recommendation was to continue the current treatment and to monitor the patient for signs of possible meningitis and cervical myositis. Muscle relaxants were also recommended with physiotherapy for the neck in the future. Infectious disease also saw the patient and recommended increasing the dose of clindamycin to $600 \mathrm{mg}$ to cover for possible retropharyngeal infection. It was also recommended that the patient stay one more night for pain control and to monitor his condition. On hospital day 3, the patient improved. Infectious disease recommended discontinuation of antibiotics at discharge and a follow-up MRI or CT to evaluate for retropharyngeal fluid collection in $2-3$ days if there was further concern. The patient was discharged home with a prescription for ibuprofen $400 \mathrm{mg}$ PO TID, antibiotics were stopped, and the patient was given the final diagnosis of retropharyngeal tendonitis.

\section{Discussion}

Thought by many to be under diagnosed, two recent studies have attempted to clarify the true incidence of retropharyngeal tendonitis. The first from Danish Chiropractors Hviid et al attempted to retrospectively determine the number of cases, of which they found 45 from 1989 to 2006 [5]. Although the study admits to several shortcomings causing them not to find a true prevalence, Horowitz et al [9] through a more systematic approach found eight new cases over a 3 -year period compared to only one documented retropharyngeal abscess. They calculated the incidence of retropharyngeal tendonitis to be 0.50 cases per 100,000 persons-year, challenging whether this was indeed as rare as previously thought [9].

Often in the practice of emergency medicine, the more impending and life-threatening conditions tend to overshadow all others when examining patients. In any patient with neck pain and a unilateral swelling, it has long been ingrained that the possibility of a retropharyngeal abscess must be quickly accessed before it can impinge the airway. While clinically they present with similar symptoms, studies have also shown multiple cases have been misread through imaging [10]. Vollmann et al concluded that although retropharyngeal tendonitis was best seen on MRI, a non-contrast CT was still the preferred imaging, due to its ability to also differentiate an abscess [10]. CT imaging is preferred in distinguishing retropharyngeal tendonitis from abscess because of its ability to show tendon swelling and retropharyngeal calcification at $\mathrm{C} 2-\mathrm{C} 4$ [11]. Retropharyngeal abscess, however, will characteristically show a well-delineated enhanced ring surrounding non-enhancing density [12].

Retropharyngeal tendonitis must be distinguished from retropharyngeal abscess, which is considered a medical emergency and requires treatment [13]. Once a diagnosis has been made preferably by CT scan, steroids and NSAIDs should be started immediately and the patient be discharged home [14]. The mainstay of treatment is $1-2$ weeks of NSAIDs and analgesics, significantly reducing patient morbidity. In contrast, retropharyngeal abscess usually requires surgical drainage and a course of antibiotics [15].

Retropharyngeal tendonitis, although uncommon, requires a high level of suspicion. When misdiagnosed, patients can often undergo unnecessary and invasive surgical procedures to drain nonexistent abscesses. With proper imaging, and an informed physician, correct diagnosis can be made based on prevertebral swelling and calcification. While this disease is self-limiting, it can often last several weeks and be very de- 
bilitating to the patient.

\section{Conflicts of Interest}

The authors declare that there are no conflicts of interest regarding the publication of this article.

\section{References}

1. Hartley J. Acute Cervical Pain Associated with Retropharyngeal Calcium Deposit. A Case Report. J Bone Joint Surg Am. 1964;46:1753-1754.

2. Eastwood JD, Hudgins PA, Malone D. Retropharyngeal effusion in acute calcific prevertebral tendinitis: diagnosis with CT and MR imaging. AJNR Am J Neuroradiol. 1998;19(9):1789-1792.

3. Hall FM, Docken WP, Curtis HW. Calcific tendinitis of the longus coli: diagnosis by CT. AJR Am J Roentgenol. 1986;147(4):742-743.

4. Queinnec S, Petrover D, Guigui P, Ilharreborde B. Benign febrile cervicalgia due to calcific retropharyngeal tendinitis: case study. Orthop Traumatol Surg Res. 2011;97(3):341-344.

5. Hviid C, Salomonsen M, Gelineck J, Rasmussen LR, Jensen KM, Kryger-Baggesen P, Hartvigsen J. Retropharyngeal tendinitis may be more common than we think: a report on 45 cases seen in Danish chiropractic clinics. J Manipulative Physiol Ther. 2009;32(4):315320.

6. Martindale JL, Senecal EL. Atraumatic neck pain and rigidity: a case of calcific retropharyngeal tendonitis. Am J
Emerg Med. 2012;30(4):636 e631-632.

7. Inokuchi R, Wada T, Ohta F, Sonoo T, Aoki Y, Asada T, Hiruma T, et al. Images in emergency medicine. A healthy young man with neck sprain. Retropharyngeal tendonitis. Ann Emerg Med. 2014;63(1):86, 95.

8. Roldan CJ, Carlson PJ. Longus colli tendonitis, clinical consequences of a misdiagnosis. Am J Emerg Med. 2013;31(10):1538 e1531-1532.

9. Horowitz G, Ben-Ari O, Brenner A, Fliss DM, Wasserzug $\mathrm{O}$. Incidence of retropharyngeal calcific tendinitis (longus colli tendinitis) in the general population. Otolaryngol Head Neck Surg. 2013;148(6):955-958.

10. Vollmann R, Hammer G, Simbrunner J. Pathways in the diagnosis of prevertebral tendinitis. Eur J Radiol. 2012;81(1):114-117.

11. Trendel D, Bonfort G, Lapierre-Combes M, Salf E, Barberot JP. Acute severe neck pain and dysphagia following cervical maneuver: diagnostic approach. Eur Ann Otorhinolaryngol Head Neck Dis. 2014;131(2):135-138.

12. Nazir KA, Fozia PA, Ul Islam M, Shakil A, Patigaroo SA. Paediatric acute retropharyngeal abscesses: an experience. Afr J Paediatr Surg. 2013;10(4):327-335.

13. Favrett A, Zanelli E, Germani C, Giorgi R, Grasso DL, Ventura A. A significant increase in potentially lifethreatening disease: retrophparyngeal abscess. Acta Paed. 2013;102:e389-e391.

14. Pollak N, Wexler S. Retropharyngeal calcific tendonitis mimics a retropharyngeal abscess. Case Rep Otolaryngol. 2013;2013:818561.

15. Kusunoki T, Muramoto D, Murata K. A case of calcific retropharyngeal tendinitis suspected to be a retropharyngeal abscess upon the first medical examination. Auris Nasus Larynx. 2006;33(3):329-331. 